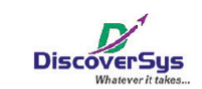

Published by DiscoverSys

\section{Length of caring duration increases burden and reduces health status of cancer patients' family caregivers in Surabaya, Indonesia}

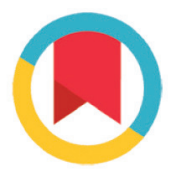

CrossMark

\author{
Yesiana Dwi Wahyu Werdani ${ }^{1^{*}}$
}

\begin{abstract}
Background and purpose: The duration of care taking of cancer patients can trigger stress which impacts on the emergence of a burden which further affects the physical health of the family caregivers. This study aims to determine the effect of caring duration on the burden and health status of cancer patient's family caregivers.

Methods: This was a cross-sectional study. Samples were 56 cancer patient's family caregivers who were selected by a purposive sampling technique based on specified inclusion criteria from two public health centers (PHCs) in Surabaya Indonesia. Participants completed the questionnaire which comprised of questions on caring duration, caregiver burden scale and physical health status. Statistical tests using simple linear regression and multiple linear regression were performed.

$(S D=12.24)$, mostly female $(66.7 \%)$, while half of the patients (51.8\%) were a stage III cancer patients and the most frequent type of therapy (35\%) received was chemotherapy. The average of caring duration was $4.44(S D=1.92)$ years, score of burden was $51.07(S D=18.45)$ and score health status was $60.32(S D=10.81)$. After adjusted for age, gender, cancer stage and type of therapy, caring duration was significantly associated with increased burden of family caregivers $(b=9.186,95 \% \mathrm{Cl}: 7.85-10.10, \mathrm{p}<0.001)$ and with reduced health status $(b=5.282,95 \% \mathrm{Cl}: 4.50-5.85, \mathrm{p}<0.001)$ Conclusion: The longer caring duration of cancer patients causes a higher burden and also a lower health status of family caregivers. Health workers and community have an important role in reducing the burden and improving the health status of caregivers by providing supports and appropriate prevention measures.
\end{abstract}

Results: The average age of family caregivers was 49.91
${ }^{1}$ Faculty of Nursing, Widya Mandala Catholic University, Surabaya

\footnotetext{
*Correspondence to: Yesiana Dwi Wahyu Werdani; Faculty of Nursing, Widya Mandala Catholic University, Surabaya; ywerdani@yahoo.com
}

Keywords: Caring duration, burden, health status, caregiver, cancer Cite this Article: Werdani, Y.D.W. 2020. Length of caring duration increases burden and reduces health status of cancer patients' family caregivers in Surabaya, Indonesia. Public Health and Preventive Medicine Archive 8(1): 53-59. D0l: 10.15562/phpma.v8i1.245

\section{INTRODUCTION}

Cancer patients, on the progression of their illness usually experience physical function limitations to carry out daily activities. ${ }^{1}$ Fatigue is one of the causes of physical limitation in cancer patients to carry out routine daily activities. Increased fatigue can result in a decreased ability to do day to day activities. $^{2}$ With limitations to carry out daily activities, cancer patients require support and help from a caregiver, who are often a family member. Family caregivers of cancer patients usually assist with patient's daily life activities including bathing, eating, toileting, and instrumental activities of daily life such as shopping, driving, managing finances and medical/nursing tasks. ${ }^{3}$

A study in Vietnam stated that the majority of cancer patients tend to experience a high level of dependence in fulfilling their daily living activities which lead to the increased burden of the family caregivers. ${ }^{4}$ The family caregivers who taking care of cancer patients are likely to experience increased psychological burden with symptoms of anxiety and depression which can affect their quality of life. ${ }^{5}$ The duration of caregiving causes high levels of caregiver depression and the emergence of various physiological disorders such as sleep disorders, increased systolic and diastolic blood pressure, increased heart rates, and changes in the cardiovascular system. ${ }^{6}$

In developed countries setting such as the United States (U.S), the majority of cancer caregivers are women (58\%), and most have undergraduate education background (60\%). The average age of caregivers for cancer patients is 53 years old ( 4 years older than non-cancer caregivers). Most caregivers of cancer patients provide care to families (88\%), while $60 \%$ provide care for the elderly who are not family members. Cancer caregivers spend an average of 32.9 hours a week of taking care patients, however, $32 \%$ of caregivers spend longer time than the average with 41 hours a week or more on taking care patients, which is equivalent to full-time working hours. ${ }^{3}$ 
Most family caregivers carry out the responsibility of caring for cancer patients at home according to their knowledge and abilities without proper training and preparation, which is likely to cause stress and anxiety. ${ }^{7}$ A study reported the depriving physical condition of a cancer patient aggravates the physical, emotional and social conditions experienced by the caregiver. ${ }^{8}$ Family caregivers who provide longer hours and involved in a longer caring period for patients with chronic and terminal diseases reported a higher levels of burden. ${ }^{9}$ A study reported that caregivers who take care cancer patient 11-20 hours/day experienced psychological distress such as unhappiness, hopelessness, stress and had tendency to cry. ${ }^{10}$

The degree of burden of a caregiver can be influenced by the quality of relationship between the caregiver and the patients. When the quality of their relationship is not good enough, the caregivers may experience a higher burden. ${ }^{11} \mathrm{~A}$ burden suffered by someone can trigger stress. Chronic stress can cause a decrease in the immune system and induce various health deprivations. ${ }^{12}$ During stress, the amygdala signals the brain stem to release sympathetic adrenergic catecholamine, norepinephrine and epinephrine. ${ }^{13}$ After being released into the bloodstream, catecholamine will increase the heart rate, blood pressure, and respiratory frequency, induce arterioles vasoconstriction and stimulates sweat secretion and dilation of the pupils. ${ }^{14}$ Inflammation caused by stress has also been proven to trigger various diseases such as chronic fatigue syndrome, chronic pelvic pain and chronic low back pain. ${ }^{15}$

Caregivers often experience physical symptoms including insomnia, fatigue, and reduced health condition because of the pressure of the caring process. ${ }^{16}$ Most of previous studies looked at the burden on family caregivers who were taking care patients with chronic/terminal illness, while burden arising from caregivers after taking care cancer patients was only presented superficially. Moreover, there is no study to date in Indonesia that explores the interrelated duration of care, burden, and health status among caregivers of cancer patients. The purpose of this study was to determine the effect of caring duration on the burden and health status of cancer patient's family caregivers.

\section{METHODS}

This was a cross-sectional study. The sampled population was all family caregivers who taking care of cancer patients at two public health centers (PHCs), Kedungdoro PHC and Pacarkeling PHC, in Surabaya, Indonesia amounted to 60 people. The sampling method used was purposive sampling.
Number of samples who were finally involved in the study was 56 people who met the inclusion criteria including age of family caregiver over 25 years old, have been caring for cancer patients for at least 1 year and family caregiver live together (at the same house) with the cancer patients.

The independent variable was the caring duration. Caring duration defined as the time that has been used by a family caregiver (in years) to provide care to family members who suffer from cancer. The dependent variables were burden and health status. The burden was a psychological response experienced by a family caregiver while caring for family members who suffer from cancer. Health status was physical health conditions experienced by a family caregiver while caring for family members suffering from cancer. Other variables collected were age (years), gender, stage of cancer and types of therapy received by the patients.

The information on caring duration and socio-demographic characteristics were collected by asking the family caregivers directly using a questionnaire. For the caregivers' burden, the instrument consists of 20 negative closed-ended questions with 5 answer options (score $4=$ always, score $3=$ often, score $2=$ sometimes, score $1=$ rare and score $0=$ never). The content of the questionnaire comprises of the impact of caring process on the physical, psychological, social and financial dimensions of caregivers. The range of scores of the caregivers' burden scale was $0-80$, with the higher score indicates the higher burden experienced by the family caregiver and the lower score indicates less burden. The validity and reliability of test results on the caregiver burden scale instrument were $\mathrm{R}=0.665-0.923$ and Cronbach's alpha $=0.931$, signifying good validity and reliability. The caregivers' burden was then analyzed on a numeric scale.

The questionnaire on health assessment consists of 21 negative closed-ended questions with 4 answer options (score 4=always, score $3=$ often, score $2=$ sometimes and score $1=$ never). The content of the questionnaire comprises of health complaints felt by the caregivers while providing care to patients. These complaints consist of complaints in the respiratory system, cardiovascular, nerve, digestive, urinary, musculoskeletal, integumentary and sensory perception. The range of score of health assessment questionnaire was 21-84. The higher score indicates the worse health status experienced by the family caregivers and the lower score indicates better health status. The validity and reliability of test results of this instrument were $\mathrm{R}=0.722-0.910$ and Cronbach's alpha $=0.918$, showing good validity and reliability. The health 
status was also analyzed in a numeric scale.

Respondents were asked to fill in all questionnaires, then the calculation of the total score was conducted. The normal distribution of the data was showed by the Kolmogorov-Smirnov test $(\mathrm{p}>0.05)$. The $\mathrm{p}$ value of normal distribution test for caring duration was 0.091 , burden was 0.066 , and health status was 0.071 . The data was then analysed descriptively, followed by simple linear regression, which aims to find the effect of each variable on the burden and health status of the cancer patient's family caregiver. Linear regression test was used to measure the effect of the independent variable on the dependent variable with interval/ratio scale data which has met normal distribution assumption. ${ }^{17}$ Then, multiple linear regression was conducted to measure the effect of caring duration to burden and health status, adjusted for the demographic variables, cancer stage and types of therapy.

This study was approved by the Medical Faculty Health Research Ethics Committee of Widya Mandala Catholic University Surabaya and has been declared ethical with the registered number: 0088/ $\mathrm{WM} 12 / \mathrm{Q} / 2018$. The research ethics procedure has also been carried out through explaining the research objectives, benefits, research procedures, side effects, confidentiality and volunteerism to prospective participants. Participants who have understood the explanation and were willing to participate in the study then signed an informed consent sheet.

Table 1. Characteristics of the family caregivers and cancer patients

\begin{tabular}{lcc}
\hline \multicolumn{1}{c}{ Demographic data } & $\mathbf{n}$ & $\%$ \\
\hline Age (years) (Mean \pm SD) & \multicolumn{2}{c}{$49.91 \pm 12.24$} \\
Gender & 37 & 66.1 \\
Female & 19 & 33.9 \\
Male & & \\
Cancer stage & 6 & 10.7 \\
Stage I & 14 & 25.0 \\
Stage II & 29 & 51.8 \\
Stage III & 7 & 12.5 \\
Stage IV & & \\
Cancer therapy & 21 & 37.5 \\
Chemotherapy & 18 & 32.1 \\
Chemo-radiotherapy & 17 & 30.4 \\
Radiation & & \\
\hline
\end{tabular}

Table 2. Caring duration, burden and health status of family caregivers

\begin{tabular}{lccc}
\hline \multicolumn{1}{c}{ Variables } & Min-Max & Mean & SD \\
\hline Caring duration (years) & $1.00-8.00$ & 4.44 & 1.92 \\
Burden & $20.00-80.00$ & 51.07 & 18.45 \\
Health status & $42.00-78.00$ & 60.32 & 10.81 \\
\hline
\end{tabular}

\section{RESULTS}

The mean age of the caregivers who participated in the study was $49.91(\mathrm{SD}=12.24)$ years which fall into the age category of an older adult, and most caregivers were female (66.7\%). Meanwhile, half of the patients $(51.8 \%)$ were a cancer stage III patients and most of them (37.5\%) were undergoing chemotherapy (Table 1 ).

Table 2 shows that the mean of caring duration was $4.44(\mathrm{SD}=1.92)$ years, with the longest of 8 years. The mean score of burden was $51.07(\mathrm{SD}=18.45)$ of the total score of 80 , signify that majority of family caregivers had a moderate burden. The mean of health status score was $60.32(\mathrm{SD}=10.81)$ of the possible highest score of 84 , which means the majority of family caregivers had fair health status.

Table 3 shows the results of simple linear regression of the independent and controlled variables with the dependent variables, burden and health status. Caring duration, age of caregivers, cancer stage and types of therapy were having moderate to strong association with both caregivers' burden (correlation coefficient ranged from 0.280.97 ) and health status (correlation coefficient ranged from 0.28-0.97). Based on the regression coefficient, a one-year increase of caring duration, will increase the score of burden by 9.3 points and score of health status by 5.44 points. A oneyear increase of caregivers' age is associated with 0.65 and 0.39 -unit increased score of burden and health status, respectively. Moreover, one-category increase of cancer stage is associated with 21.41 points increase of burden and 12.52 points increase of health status scores.

In comparison with caregivers of patients with radiotherapy, caregivers of patients with chemotherapy have 12.76 points higher score of burden; while those with combination of chemo and radiotherapy have 10.70 higher points of burden. Similarly, caregivers of patients with chemotherapy have 7.25 points higher score of health status; while those with combination of chemo and radiotherapy have 6.4 higher points of burden than the caregivers of patients with radiotherapy.

From the multiple linear regression analysis (Table 4), after being adjusted for the controlled variables, only caring duration was associated with both burden and health status with coefficient determination of 0.94 , signifying length of caring duration predicts $94 \%$ of the variation of both burden and health status. Based on the regression coefficient, a one-year increase of caring duration will increase score of burden by 8.97 points $(95 \% \mathrm{CI}$ : 7.85-10.10). Meanwhile for health status, a oneyear increase of caring duration will increase score of health status by 5.18 points (95\%CI: $4.50-5.85$ ), 
Table 3. Association between caring duration, family caregivers and patients' characteristics with burden and health status

\begin{tabular}{|c|c|c|c|c|c|c|c|c|}
\hline \multirow{2}{*}{ Variables } & \multicolumn{4}{|c|}{ Burden } & \multicolumn{4}{|c|}{ Health Status } \\
\hline & $\mathbf{r}$ & $\mathbf{b}$ & $95 \% \mathrm{Cl}-\mathrm{b}$ & $\mathbf{p}$ & $\mathbf{r}$ & B & $95 \% \mathrm{Cl}-\mathrm{b}$ & $\mathbf{p}$ \\
\hline Caring duration (years) & 0.97 & 9.29 & $8.64-9.4$ & $<0.001$ & 0.97 & 5.44 & $5.05-5.83$ & $<0.001$ \\
\hline Age (years) & 0.43 & 0.65 & $1.42-1.56$ & 0.001 & 0.44 & 0.39 & $0.83-0.91$ & 0.001 \\
\hline Gender & 0.10 & -4.01 & $-14.49-6.47$ & 0.446 & 0.13 & -2.88 & $-9.01-3.25$ & 0.351 \\
\hline Cancer stage & 0.64 & 21.41 & $18.55-24.27$ & $<0.001$ & 0.65 & 12.52 & $10.82-14.21$ & $<0.001$ \\
\hline $\begin{array}{l}\text { Cancer therapy } \\
\text { - Radiotherapy } \\
\text { - Chemotherapy }\end{array}$ & $\begin{array}{c}\text { ref } \\
0.39\end{array}$ & 12.76 & $3.060-22.46$ & 0.011 & 0.33 & 7.25 & $1.54-12.96$ & 0.014 \\
\hline - Chemo-radiotherapy & 0.28 & 10.70 & $0.423-20.98$ & 0.04 & 0.28 & 6.40 & $0.388-12.41$ & 0.037 \\
\hline
\end{tabular}

$r=$ correlation coefficient, $b=$ unstandardized regression coefficient, $95 \% C I-b=95 \%$ confidence interval for the coefficient regression

Table 4. Adjusted effect of caring duration on burden and health status

\begin{tabular}{|c|c|c|c|c|c|c|c|c|}
\hline \multirow{2}{*}{ Variables } & \multicolumn{4}{|c|}{ Burden } & \multicolumn{4}{|c|}{ Health Status } \\
\hline & b & $95 \% \mathrm{Cl}-\mathrm{b}$ & $\mathbf{p}$ & $\mathbf{R}^{2}$ & b & $95 \% \mathrm{Cl}-\mathrm{b}$ & $\mathbf{p}$ & $\mathbf{R}^{2}$ \\
\hline Caring duration & 8.97 & $7.85-10.10$ & $<0.001$ & 0.943 & 5.18 & $4.50-5.85$ & $<0.001$ & 0.940 \\
\hline Age & -0.01 & $-0.13-0.12$ & 0.908 & & 0.01 & $-0.07-0.08$ & 0.879 & \\
\hline Gender & 0.17 & $-2.56-9.90$ & 0.901 & & -0.53 & $-2.17-1.11$ & 0.519 & \\
\hline Cancer stage & 1.33 & $-0.86-3.51$ & 0.229 & & 0.99 & $-0.32-2.31$ & 0.133 & \\
\hline $\begin{array}{l}\text { Cancer therapy } \\
\text { - Radiotherapy } \\
\text { - Chemotherapy } \\
\text { - Chemo-radiotherapy }\end{array}$ & $\begin{array}{c}\text { ref } \\
1.10 \\
-1.03\end{array}$ & $\begin{array}{l}-2.92-5.11 \\
-5.12-3.06\end{array}$ & $\begin{array}{l}0.585 \\
0.616\end{array}$ & & $\begin{array}{c}\text { ref } \\
0.34 \\
-0.64\end{array}$ & $\begin{array}{l}-2.07-2.75 \\
-3.10-1.82\end{array}$ & $\begin{array}{l}0.778 \\
0.604\end{array}$ & \\
\hline
\end{tabular}

$\mathrm{b}=$ unstandardized regression coefficient, $95 \% \mathrm{CI}-\mathrm{b}=95 \%$ confidence interval for the coefficient regression, $\mathrm{R}^{2}=$ determination coefficient

signifying a decrease in health status since the higher score of health status reflects poorer health.

\section{DISCUSSION}

We found that caring duration has a significant effect on both the burden and health status of family caregivers. Similar results were reported by a study of acute lymphoblastic leukaemia caregivers that also found high scores of caregiver burden. ${ }^{18} \mathrm{~A}$ study of 108 informal caregivers also reported a high care burden during taking care of cancer patients. ${ }^{19}$ Taking care patients with a terminal illness increased psychological pressure and reduced quality of life due to the burden of caregiving. ${ }^{20}$

Caregivers who provide long-term care can experience compassion fatigue. They may feel upset about the caregiving situation, helpless and hopeless about the caregiving process. ${ }^{21}$ This finding is also supported by a study of 306 caregivers who take care patients with a terminal illness for a long time. The caregivers experienced a high level of difficulty in taking care patients who have pain, which led to higher level of burden. ${ }^{22}$
We also found that the burden and health status were associated with the stage of cancer and therapy undertaken by the cancer patients. Most cancer patients treated by caregivers were in stage III and received chemo-radiotherapy. The most appropriate treatment to the stage III cancer patients was indeed by giving adjuvant chemotherapy, ${ }^{23}$ however, oxidative stress-mediated by cancer or chemotherapy agents, affects the decrease in muscle strength which causes weakness. ${ }^{24}$ Similarly, stage I-III breast cancer patients who received surgery, radiotherapy, chemotherapy and hormonal therapy also experienced decreased joint mobility, reduced muscle strength, pain, lymphedema and limitations in daily activities. ${ }^{25}$

Cancer patients who experience physical weakness, need caregivers' assistance in carrying out their routine activities. The daily activities of cancer patients who are assisted by caregivers include eating, dressing, bathing, doing household chores such as cooking, shopping, ${ }^{26}$ providing drugs, providing transportation, preparing food, managing finances, advocating for health care and providing emotional support. ${ }^{27}$ Caregiving process 
carried out by caregivers ranging from mild to complex process, wherein the more complex type of care provided to the cancer patient causes the caregiver to have moderate-severe burden. ${ }^{28}$

Based on a cross-sectional study of 153 caregivers, factors correlated with the high caregiver burden was the degree of patient's dependence on caregivers. ${ }^{29}$ Another study of 200 cancer patients' family caregivers found $37.5 \%$ of them reported mild to moderate burden due to the caregiving process. ${ }^{30}$ The source of caregiver burden was the complex needs of patients who must be assisted by the caregivers. Moreover, the monitoring of patient's condition for a long time further makes the caregivers set aside their personal needs which may cause frustration of the caregivers. ${ }^{31}$ The caregivers' burden is a multidimensional biophysical reaction as a result of an imbalance of patient care demands for caregiver's time, social role, physical and emotional state, financial resources and formal care resources. ${ }^{32}$ Caring for cancer patients can cause physical fatigue in caregivers. The most frequent symptom experienced by cancer patient's caregivers was fatigue due to providing long hours and long term cares. ${ }^{33} \mathrm{~A}$ study explained that higher caregiver fatigue scores have a significant relationship with increased depression, anxiety and caregivers' sleep disorders. ${ }^{34}$

Caregivers' burnout is a response to stress as indicated by the emergence of emotional fatigue as a feeling of being overloaded, no longer able to continue cares and emotionally drained when faced with caregiving situations. ${ }^{35}$ The caregivers in this study was dominated by females. Evidence shows that women were more susceptible to stress. Female caregivers tend to suffer a greater burden than male caregivers because women have more responsibilities to care and may experience feelings of guilt if they don't provide proper care for their families. ${ }^{36}$

We also found that the caring duration has a significant effect on health status. Caregivers for patients with cancer are prone to experience reduced health status and work disorders. ${ }^{37}$ Caregivers who experience increased burden were also likely to experience symptoms of depression. ${ }^{38}$ Similar results were revealed in a study among cancer patients caregivers undergoing palliative care when $82 \%$ of the caregivers reported moderate stress and $18 \%$ had severe stress. ${ }^{39}$ The finding of this study also showed that the mean age of caregivers was 49.91 years, and age was significantly associated with health status. Another study reported that older adults have a high risk of decreasing physical health conditions, ${ }^{40}$ and the vulnerability to experience stress in doing work as a caregiver. ${ }^{41}$
Chronic stress can cause disruption of circadian rhythms and mild increases of cortisol at night, so, the clock of gene mechanism of circadian regulation on the Hypothalamic Pituitary Adrenal (HPA) Axis is disrupted and individuals can experience sleep disorders such as insomnia. ${ }^{42}$ Anxiety and depression can trigger heart disease, asthma, vision problems, persistent cough, hypertension and digestive problems. ${ }^{43}$ The response of human body to stress is by triggering the release of epinephrine, norepinephrine and the cortisol hormone. Cortisol functions to mobilize glucose reserves for energy and modulate inflammation. ${ }^{44}$ Increased stressinduced cortisol secretion that occurs in the long term has a detrimental effect on human physical and psychological functions. ${ }^{45}$

The emergence of cortisol as a result of stress can decrease immunity and stimulate activity of the HPA axis through direct cytokine action in the brain and by inducing glucocorticoid resistance, oxidative and free radical damage, cell death, aging and systemic tissue degeneration. ${ }^{46}$ When reactive oxygen species (ROS) production increases, it begins to show a harmful effect on important cellular structures such as proteins, lipids, and nucleic acids. ${ }^{47}$ Free radicals are caused by an imbalance between antioxidants and oxidants. Free radicals cause damage to strong macromolecules such as nucleic acids, proteins, and lipids, that cause tissue damage and the emergence of various diseases such as diabetes mellitus, neurodegenerative diseases, cancer, cardiovascular diseases, cataracts, rheumatoid arthritis and asthma. ${ }^{48}$ Caregivers who take care cancer patients for a long time can experience increased blood pressure, autonomic nervous system, hypothalamic-pituitary axis disorder, immune changes and health-related bad behaviour. ${ }^{49}$

The study findings have important implications for health workers and other stakeholders to reduce the burden of the family caregivers. Building stronger relationships between health workers, surrounding community and family caregivers can facilitate caregivers to have positive emotions, which may reduce the caregivers' burden. ${ }^{50}$ Improving the health status of family caregivers is also an important responsibility of health workers, therefore, new approaches to improve family caregivers' health status should be explored. A study mentioned the implementation of nurses as educators, loving caregivers and supporters were very helpful in increasing the physical and psychological wellbeing of caregivers during the process of caring for patients with chronic illnesses. ${ }^{51}$

The limitations of this study were the small number of participants and the limited number 
of PHC involved, in which only two PHCs in Surabaya. The results may not fully represent the condition of family caregivers who taking care the cancer patients, therefore, generalisability of the results should be taken with precaution. In the future, exploration with bigger samples and broader area of Indonesia should be conducted, as well as qualitative exploration to get a more in-depth and better pictures on the family caregivers' well-being and how to improve it.

\section{CONCLUSION}

We found that the duration of cares is associated with the burden and health status of family caregivers. The longer caring duration of cancer patients causes a higher burden and reduced health status of the family caregivers. We recommend the health workers to not only pay attention to the patient's condition but also to the well-being of caregivers, to the quality of care provided by a family caregiver in order to achieve a better condition of both the patients and the caregivers.

\section{ACKNOWLEDGEMENTS}

I greatly appreciate and thank for the cooperation and assistance provided by the PHCs' staff and all participants from two PHCs in Surabaya namely Kedungdoro PHC and Pacarkeling PHC. I also thank the Dean of the Faculty of Nursing and Widya Mandala Catholic University as a funder who has contributed to the research and the Ethics Committee of Medical Faculty of Widya Mandala Catholic University.

\section{AUTHOR CONTRIBUTION}

YW conceived the idea, gathered the theory and developed research methodology, carried out the data collection, verified the statistical analytic, interpreted the results and wrote the manuscript.

\section{CONFLICT OF INTEREST}

I declare there is no conflict of interest

\section{FUNDING}

This research received internal funding from the Widya Mandala Catholic University Surabaya, Indonesia.

\section{REFERENCES}

1. Braithwaite D, Satariano WA, Sternfeld B, Hiatt RA, Ganz $\mathrm{PA}$, Kerlikowske $\mathrm{K}$, et al. Long-term prognostic role of functional limitations among women with breast cancer. $J$ Natl Cancer Inst. 2010;102(19):1468-1477.

2. Jim HSL, Small B, Faul LA, Franzen J, Apte S, Jacobsen
PB. Fatigue, depression, sleep, and activity during chemotherapy: Daily and intraday variations and relationships among symptom changes. Ann Behav Med. 2011;42(3):321-33.

3. National Alliance for Caregiving. Caregiving in the U.S. 2015;(April):1-83.

4. Nguyen LT. Caregiving burden among relatives of cancer patients in Vietnamese National Oncology Hospital. Vietnam J Meidicine Pharm. 2015;8(2):1-14.

5. Borges EL, Franceschini J, Costa LHD, Fernandes ALG, Jamnik S, Santoro IL. Family caregiver burden: the burden of caring for lung cancer patients according to the cancer stage and patient quality of life. J Bras Pneumol. 2017;43(1):18-23.

6. Corà $\mathrm{A}$, Partinico $\mathrm{M}, \mathrm{Munafò} \mathrm{M}$, Palomba $\mathrm{D}$. Health risk factors in caregivers of terminal cancer patients: A pilot study. Cancer Nurs. 2012;35(1):38-47.

7. Given BA, Given CW, Sherwood PR. Family and caregiver needs over the course of the cancer trajectory. J Support Oncol. 2012;10(2):57-64

8. Soliman HH, Almotgly MMA. Psychosocial profile of people with AIDS and their caregivers in Egypt. Psychol Rep. 2011;108(3):883-892.

9. Datta S, Kar S. Assessing health and quality of life burden on caregivers of chronically and terminally ill patientsEvidence based systematic review from a global perspective. Athens J Heal. 2016;3(4):319-334.

10. Akpinar NB, Yurtsever S. Care burden and quality of life of family members caring for cancer outpatients. Int J Caring Sci. 2018;11(3):1516-1525.

11. Barnard A, Clur L, Joubert Y. Returning to work: The cancer survivor's transformational journey of adjustment and coping. Int J Qual Stud Health Well-being. 2016;11:32488.

12. Salleh MR. Life event, stress and illness. Malaysian J Med Sci. 2008; 15(4):9-18.

13. Sorrells SF, Caso JR, Munhoz CD, Sapolsky RM. The stressed CNS: When glucocorticoids aggravate inflammation. Neuron. 2009;64(1):33-9.

14. Vinik AI, Maser RE, Ziegler D. Autonomic imbalance: prophet of doom or scope for hope? Diabet Med. 2011;28(6):643-51

15. Tak LM, Rosmalen JGM. Dysfunction of stress responsive systems as a risk factor for functional somatic syndromes. $J$ Psychosom Res. 2010;68(5):461-8.

16. Sun V, Grant M, Koczywas M, Freeman B, Zachariah F, Fujinami R, et al. Effectiveness of an interdisciplinary palliative care intervention for family caregivers in lung cancer. Cancer. 2015;121(20):3737-3745.

17. Kumari K. Linear regression analysis study. J Pract Cardiovasc Sci. 2018;4(1):33-36.

18. Kumari R, Kohli A, Malhotra P, Grover S, Khadwal A. Burden of caregiving and its impact in the patients of acute lymphoblastic leukemia. Ind Psychiatry J. 2018;27(2):249258.

19. Gabriel IO. Caregiver burden among informal caregivers of women with breast cancer. Biomed J Sci Tech Res. 2019;15(3):11384-11392.

20. Wen F-H, Chen J-S, Chou W-C, Chang W-C, Shen WC, Hsieh C-H, et al. Family caregivers' subjective caregiving burden, quality of life, and depressive symptoms are associated with terminally ill cancer patients' distinct patterns of conjoint symptom distress and functional impairment in their last six months of life. J Pain Symptom Manage. 2019;57(1):64-72.

21. Perry B, Dalton JE, Edwards M. Family caregivers' compassion fatigue in long-term facilities. Nurs Older People. 2010;22(4):26-31.

22. Ishii $\mathrm{Y}$, Miyashita M, Sato K, Ozawa T. A family's difficulties in caring for a cancer patient at the end of life at home in 
Japan. J Pain Symptom Manage. 2012;44(4):552-562.

23. Miller KD, Nogueira L, Mariotto AB, Rowland JH, Yabroff $\mathrm{KR}$, Alfano CM, et al. Cancer treatment and survivorship statistics, 2019. CA Cancer J Clin. 2019;69(5):363-385.

24. Gilliam LAA, St. Clair DK. Chemotherapy-induced weakness and fatigue in skeletal muscle: The role of oxidative stress. Antioxid Redox Signal. 2011;15(9):25432563.

25. Hidding JT, Beurskens CHG, van der Wees PJ, van Laarhoven HWM, Nijhuis-van der Sanden MWG. Treatment related impairments in arm and shoulder in patients with breast cancer: A systematic review. PLoS One. 2014;9(5):e96748.

26. Glajchen M. Physical well-being of oncology caregivers: an important quality-of-life domain. Semin Oncol Nurs. 2012;28(4):226-235.

27. Bevans M, Sternberg EM. Caregiving burden, stress, and health effects among family caregivers of adult cancer patients. JAMA. 2012;307(4):398-403.

28. Werdani YDW. Effect of caregiving in cancer patient on the level of caregiver burden. J Ners dan Kebidanan (Journal Ners Midwifery). 2018;5(3):249-256.

29. Abdollahpour I, Noroozian M, Nedjat S, Majdzadeh R. Caregiver burden and its determinants among the family members of patients with dementia in Iran. Int J Prev Med. 2012;3(8):544-551.

30. Lukhmana S, Bhasin S, Chhabra P, Bhatia M. Family caregivers' burden: A hospital based study in 2010 among cancer patients from Delhi. Indian J Cancer. 2015;52(1):146.

31. Mandani B, Hosseini SA, Hosseini MA, Noori AK, Reza M, Ardakani K. Perception of family caregivers about barriers of leisure in care of individuals with chronic psychiatric disorders: a qualitative study. Electron Physician. 2018;10(3):6516-6526.

32. Grunfeld E, Coyle D, Whelan T, Clinch J, Reyno L, Earle CC, et al. Family caregiver burden: results of a longitudinal study of breast cancer patients and their principal caregivers. Can Med Assoc J. 2004;170(12):1795-1801.

33. Clark MM, Atherton PJ, Lapid MI, Rausch SM, Frost $\mathrm{MH}$, Cheville AL, et al. Caregivers of patients with cancer fatigue: a high level of symptom burden. Am J Hosp Palliat Care. 2014;31(2):121-125.

34. Fletcher BAS, Dodd MJ, Schumacher KL, Miaskowski C. Symptom experience of family caregivers of patients with cancer. Oncol Nurs Forum. 2008;35(2):23-44.

35. Thompson R, Kerr M, Glynn M, Linehan C. Caring for a family member with intellectual disability and epilepsy: Practical, social and emotional perspectives. Seizure. 2014;23(10):856-863.

36. Chappell NL, Dujela C, Smith A. Caregiver well-being: Intersections of relationship and gender. Res Aging. 2015;37(6):623-645.

37. Goren A, Gilloteau I, Lees M, daCosta DiBonaventura M. Quantifying the burden of informal caregiving for patients with cancer in Europe. Support Care Cancer. 2014;22(6):1637-1646.
38. Del-Pino-Casado R, Cardosa MR, López-Martínez C, Orgeta V. The association between subjective caregiver burden and depressive symptoms in carers of older relatives: A systematic review and meta-analysis. PLoS One. 2019;14(5):1-16.

39. Antony L, George LS, Jose TT. Stress, coping, and lived experiences among caregivers of cancer patients on palliative care: A mixed method research. Indian J Palliat Care. 2018;24(3):313-319.

40. Hsu HC. Age differences in work stress, exhaustion, wellbeing, and related factors from an ecological perspective. Int J Environ Res Public Health. 2019;16(1).

41. Carr E, Murray ET, Zaninotto P, Cadar D, Head J, Stansfeld $\mathrm{S}$, et al. The association between informal caregiving and exit from employment among older workers: Prospective findings from the UK household longitudinal study. Journals Gerontol-Ser B Psychol Sci Soc Sci. 2018;73(7):1253-1262.

42. Nader N, Chrousos GP, Kino T. Interactions of the circadian CLOCK system and the HPA axis. Trends Endocrinol Metab. 2010;21(5):277-286.

43. Kang HJ, Bae KY, Kim SW, Shin HY, Shin IS, Yoon JS, et al. Impact of anxiety and depression on physical health condition and disability in an elderly Korean population. Psychiatry Investig. 2017;14(3):240-248.

44. Hannibal KE, Bishop MD. Chronic stress, cortisol dysfunction and pain: a psychoneuroendocrine rationale for stress management in pain rehabilitation. Phys Ther. 2014;94(12):1816-1825.

45. Jankord R, Herman JP. Limbic regulation of hypothalamopituitary-adrenocortical function during acute and chronic stress. Ann N Y Acad Sci. 2008;1148(1):64-73.

46. Zunszain PA, Anacker C, Cattaneo A, Carvalho LA, Pariante CM. Glucocorticoids, cytokines and brain abnormalities in depression. Prog Neuro-Psychopharmacology Biol Psychiatry. 2011;35(3):722-729.

47. Wu JQ, Kosten TR, Zhang XY. Free radicals, antioxidant defense systems, and schizophrenia. Prog NeuroPsychopharmacology Biol Psychiatry. 2013;46:200-206.

48. Phaniendra A, Jestadi DB, Periyasamy L. Free radicals: properties, sources, targets, and their implication in various diseases. Indian J Clin Biochem. 2015;30(1):11-26.

49. Teixeira RJ, Applebaum AJ, Bhatia S, Brandão T. The impact of coping strategies of cancer caregivers on psychophysiological outcomes: an integrative review. Psychol Res Behav Manag. 2018;11:207-215.

50. Frederick D. Mitigating burden associated with informal caregiving. J Patient Exp. 2018;5(1):50-55.

51. Imanigoghary Z, Peyrovi H, Nouhi E, Kazemi M. The role of nurses in coping process of family caregivers of vegetative patients: a qualitative study. Int J Community Based Nurs Midwifery. 2017;5(1):70-81.

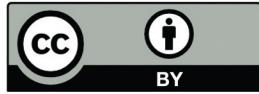

This work is licensed under a Creative Commons Attribution 